\title{
INTEGRATED APPROACH FOR EXPLORING CRITICAL ELEMENTS THAT AFFECT SUSTAINABLE DEVELOPMENT OF CULTURAL AND CREATIVE INDUSTRIES
}

\author{
Yueh-Cheng WU' ${ }^{1}$, Sheng-Wei $\operatorname{LIN}^{2}$ \\ ${ }^{1}$ Department of Cultural Vocation Development, College of Humanities and Social Sciences, \\ National Taipei University of Technology, Taipei, Taiwan \\ ${ }^{2}$ Department of Financial Management, Management College, \\ National Defense University, Taipei, Taiwan
}

Received 23 May 2020; accepted 04 December 2020

\begin{abstract}
The cultural and creative industries (CCIs) are increasingly regarded as a means to cure economic stagnation and boost sustainable development; thus, they have become the focus of cultural, social, and economic policies. This study adopts a city governance perspective to explore topics that should be considered in CCIs development. We combine entropy weight and grey relational analysis into an evaluation indicator system that considers ambiguity and complexity. The results reveal the cities in the eastern region and offshore islands took more advantage of investment in cultural resources than cities in the western region. It indicates that local governments understand that the economic benefits of culture are not limited to certain CCIs but extend to the overall economy. Through stimulus policies, communities have been built and effectively revitalized regional economies. The developed method prioritizes the provision of cultural and creative resources to effectively improve resource-generating capacity of a city. This study provides suggestions for decision makers in cultural and creative sectors to help them overcome the gap in resource allocation between urban and rural areas.
\end{abstract}

Keywords: cultural and creative industry, sustainable development, grey relational analysis, resource allocation, entropy weight, regional development.

JEL Classification: C10, C54, C61, C67.

Online supplementary material: Supporting information for this paper is available as online supplementary material at https://doi.org/10.3846/jbem.2021.14261

\section{Introduction}

Cultural and creative industries (CCIs) often codevelop, and developing countries rely on these industries to maintain economic growth. However, the primary products of these industries are the United States, the United Kingdom, and other European countries (United

${ }^{\star}$ Corresponding author. E-mail: shengwei.lin1985@gmail.com

Copyright (c) 2021 The Author(s). Published by Vilnius Gediminas Technical University

This is an Open Access article distributed under the terms of the Creative Commons Attribution License (http://creativecommons. org/licenses/by/4.0/), which permits unrestricted use, distribution, and reproduction in any medium, provided the original author and source are credited. 
Nations Conference on Trade and Development \& United Nations Development Programme, 2010). Nevertheless, the development of CCIs in East Asia has become a solution for becoming newly competitive in the global market, transforming industry, and undertaking urban revitalization (Otmazgin \& Ben-Ari, 2012; Yusuf \& Nabeshima, 2005).

As initiatives for the development of creative cities and classes have spread globally in recent years, CCIs have come to be viewed as valuable for increasing countries' competitiveness, and the scope of their value has expanded to include effects on economic, social, and sustainable development. Maryunani and Mirzanti (2015) noted that CCIs constantly expand, particularly in developed countries. The United Nations Educational, Scientific and Cultural Organization launched the "Creative Cities Network" project in 2004 to promote cultural diversity and sustainable development. The project focuses on seven elements: literature, film, music, crafts and folk art, design, media arts, and gastronomy. As of 2018, 185 cities have engaged with this network to draw upon and share experiences to strengthen local cultures and promote economic development CCIs. Many countries have proposed and stipulated their own creative city indicators to measure the development of CCIs, and this clearly indicates the central position of creative city promotion in sustainable development in various countries.

Boccella and Salerno (2016) explored the economic importance of the creative economy. Their analysis revealed that creativity facilitates necessary international policies and deepens connections between cultures, countries, and social organizations, thus enhancing the cultural and creative sectors' economic role. Culture and creativity are the core of local economic development patterns. As emphasized at the European Creative Industries Summit in 2015, "the creative economy is not only associated with large cities and dominant regions within countries, but also concentrated within cities where a prosperous creative industry sector may be a small enclave surrounded by poverty and social deprivation."

Florida (2002) noted problems such as uneven regional development resulting from the emergence of creative cities, thereby highlighting that creative city development can worsen social and economic inequality. In his inequality index, the core areas of creativity in the United States - exemplified by the top two creative regions, Austin and San Francisco - tend to exhibit the highest income inequality. Strategies for city revitalization driven by culture and creativity include refitting facilities for city culture and recreation events (Goldberg-Miller, 2019), establishing scenic spots, hosting international events and art and culture celebrations, and marketing a new urban image (Hernández-Mogollón et al., 2018). Community building policies facilitate public recognition of the close relationship between CCIs and local economic and social development (Budge, 2019). This is effective in two aspects: First, promoting local CCIs is key for any society. Second, CCIs are considered applicable tools or channels for promoting cultural conservation (Pereira Roders \& van Oers, 2011). The CCI mindset centered on local economic rejuvenation a promise to nurture local cultural resources, with the growth of the creative industry expected to simultaneously protect local cultures (Ochoa \& Ramírez, 2018). This mindset relies on a knowledge-based economy, innovation, and job creation and focuses on the achievement of economic profitability and industry transformation (Hauge et al., 2018). Consequently, establishing a model for comprehensively evaluating resource allocation policy to improve the efficiency of cultural and creative resource allocation and stimulate the economic and innovative capacity of local CCIs is necessary. 
Furthermore, addressing emerging problems, such as whether major cities are capable of accommodating CCIs, by examining simple aggregations of economic performance statistics is insufficient. Therefore, this study used Taiwanese cities as samples and creative resource allocation and Ministry of Economic Affairs statistical data as references. This study adopted entropy and grey relational analysis (GRA) to identify success-determining factors of CCIs in each city. This approach has two advantages: (1) Entropy weight can reduce the noise from man-made operations and consequently enhance fidelity and accuracy, and (2) comparative analysis between key success factors can be conducted to evaluate advantages and disadvantages of cultural development across cities. Thus, a decision-making matrix may be formulated to generate suggestions for cultural and creative resource allocation and sustainable development. The results can be applied in future research and policy development related to CCIs to maximize resource benefits.

This study expanded the research scope to enable the model to compare the characteristics and development history of cultural and creative clusters in various Taiwanese cities and townships. The findings can be used to identify requirements for sustainable cultural and creative cluster development and contribute to the application of sustainable development. This study makes the following theoretical and empirical contributions:

First, this study used a city governance perspective to explore topics that should be considered in CCI development and policy-making. Decisions on cultural development should be considered when designing economic policies. The government should conduct studies and analysis to transcend current industry segmentation and define industries, compile relevant data. During policy implementation, limited resources should be efficiently utilized, and guidance benefits should be defined alongside timely policy evaluation. Advantages, disadvantages, opportunities, and threats associated with industry and market development should be identified. For governance transformation, industry guidance strategies should be selected to precisely promote creative industry development in Taiwan and enhance its competitiveness. This study is a comprehensive examination of a model for evaluating success factors of CCIs. For industry development, this model provides a theoretical basis of CCI development for exploring and discovering statistical results. The authors constructed this evaluative model to fill a gap in understanding between government authorities and practitioners in CCIs.

By applying entropy weight and GRA to evaluate resource allocation strategies for CCIs, this study adopted an approach to make resource allocation more comprehensive, objective, and scientific, thus providing a reliable decision-making basis on which the implementation of resource allocation for CCIs can be evaluated. To ensure objective and comprehensive evaluation results, qualitative and quantitative analyses were combined.

Entropy weight can objectively define the weight of objective data and eliminate the influence of subjectivity. GRA is based on the thorough use of objective data to identify the proximity of each solution to the optimal solution to facilitate decision-making. GRA is a grey system that can address incomplete information. It is highly accurate in evaluating and defining small and irregular samples. Thus, GRA is appropriate for examining decision-making related to CCI resource allocation; can effectively avoid the influence of subjectivity and biased result evaluation; and maximize reasonable, objective, and comprehensive evaluation. 
The remainder of this paper is organized as follows: Section 1 reviews the recent literature on cultural policy for sustainable development, the circular economy, and performance evaluation of CCIs. Section 2 develops a new method for cultural resource allocation analysis. Section 3 illustrates a case study of Taiwanese counties. Finally, last Section concludes the paper and recommends research approaches for future studies.

\section{Background}

\subsection{Cultural policy for sustainable development}

Globalization continues to blur geographic boundaries between regions and countries. Sustainable development is confronted with the threat of globalization and the decline of traditional industries. Therefore, a new way of regarding city patterns has emerged. Future urban development must be freed from the restrictions of traditional concepts that emphasize constructing tangible facilities such as roads and buildings. Sustainable urban development must be human-oriented, focus on creativity, and enhance city competitiveness (Gottdiener, 2019).

In addition to manufacturing and service industries, CCIs have become new core elements of sustainable economies. CCIs should be established on the basis of the local culture's uniqueness to ensure they cannot be mass produced or reproduced (Baraldi \& Havenvid, 2016). "Localization" is a key industry attribute and uses the aggregation of community building and interdependency with the environment to retain traditional cultural connotations and local attractions. Kim (2017) indicated that creative economy-driven development has been a strategy employed by Eastern nations to regain momentum after the economic recession, which is different from the West, where CCIs emerged after the economic recession. Asian nations have begun to pay attention to cultural development amidst the pressure of globalization during their economic recoveries. The emphasis on unique city cultures facilitates creativity and constitutes a way to overcome negative fallout from globalization. Seven characteristics shared by creative cities are summarized below (Pratt, 2011; Rodrigues \& Franco, 2018):

1. Personal qualities: The primary element of creative cities is high-quality human resources. These creative talents should flow through a mutually connected channel of communication that boosts innovation.

2. Will and leadership: Creative city leaders tend to be daring, perseverant, and efficient. Visionary and creative characteristics can be conducive to creative city development.

3. Human diversity and access to varied talent: Several famous cultural pivots in European history were characterized by the development of multicultural societies where outsiders brought in new ideas, technologies, and creativity.

4. Organizational culture: City authorities constantly examine whether they are equipped with creativity, which may include ongoing demonstration programs from various organizations and departments, cross-departmental tasks, and encouragement of benign competition between city organizations. However, the city should encourage residents to learn about their surroundings and understand how changes in their social environment affect them. 
5. Local identity: Many cities with rich histories establish paths to development through creative thinking. Therefore, embracing new ideas and diversity is key to the success of a city's creativity.

6. Urban spaces and facilities: Public spaces include those that are physical and virtual. Physical public spaces are parks, museums, and squares, whereas virtual spaces are those facilitated by the Internet. Public spaces encourage communication and exchanges among social classes, ethnic groups, and occupations. Public facilities are the embodiment of multiple types of creativity. City-specific industries, the media, and seminars all are necessary prerequisites for shaping creative spaces.

7. Networking dynamics: Creative city networks are divided into intranational and international networks through which cities are connected; creativity can spread throughout entire cities.

Therefore, the true power of the creation of a local cultural industry lies in how to discover the city's local cultural potential and congregate such potential through the city's important elements. In Taiwan, the progress of a city is a reflection of overcoming the barriers caused by changes due to urbanization and globalization, and the subsequent expected creation of shared values. The development environment for CCIs can only be created through mutual communication among life, culture, and industry.

\subsection{Evaluating the performance of cultural and creative industries}

Zhang et al. (2016) indicated that the evaluation of city sustainability involves multicriteria decision-making (MCDM), in which the mutual influence and weight of interdependent criteria cannot be ascertained in a subjective and reliable manner. Therefore, they proposed an objective weighting method to define criteria weight in MCDM environments. The results of empirical studies evaluating the sustainable development of 13 cities in China have proved that the proposed method can elucidate differences in performance between cities based on various evaluation standards, which minimizes the influence of subjectivity. Bhansing et al. (2018) stated that "creativity" is used and defined in various ways, particularly in the creative industry. Culture-related policies and relevant academic literature have revealed that creative industries are often related to a city's capacity for creativity (Protogerou et al., 2017).

As a strategic emerging industry, CCIs can stimulate industry restructuring, transform economic growth, and lead to the development of new and ecofriendly cities. Lu and Chang (2016) established a political effect evaluation system for CCIs in Beijing that defines weight with entropy and analyzes its effect through fuzzy comprehensive evaluation. They concluded that industry policies have been effectively implemented in Beijing and that the beneficial effects on society and culture have consistently increased, particularly the economic benefits. Vatansever and Akgül (2018) adopted GRA to analyze questionnaires and extracted key success factors for website content design to create a reference for website operators, improve the quality of website content designs and promote website visits, and develop marketing strategies to attract more consumers. Rajesh and Ravi (2015) adopted GRA to select suppliers for flexible supply chains. Hashemi et al. (2015) created a model mixed with analytic network processing and GRA to select green suppliers in the automotive industry. 
MCDM can be evaluated in multiple ways (Zhang et al., 2016). MCDM methods are also widely applied in performance evaluation. In addition to data envelopment, many methods in performance evaluation adopt hybrid approaches; for instance, the fuzzy analytic hierarchy process plus technique for ordering preference by similarity to ideal solutions for evaluating city environmental capacity (Irankhahi et al., 2017) and mineral processing plant site selection (Safari et al., 2012). Analytic hierarchy process (AHP) is adopted alongside GRA for evaluating optimal plant information collection systems (Gangurde, 2016) or supplier performance (Wang et al., 2017). These approaches are widely used in various fields. Among all methods, GRA can model nonfunctional sequences while facilitating easy calculation, does not require large data with normal distribution, and generates results that do not conflict with quantitative analysis. Thus, this method can be flexibly applied across fields and used to posit the most effective policy choices for value creation with limited resources while avoiding overinvestment and public resource waste from intercity competition. Therefore, this study adopted GRA to explore resource allocation strategies for CCIs.

\section{Methodology}

In this study, the weights of the criteria were calculated through the entropy weight method, and then the rankings of elements affecting sustainable development were calculated through GRA. The methodological framework is presented in Figure 1.

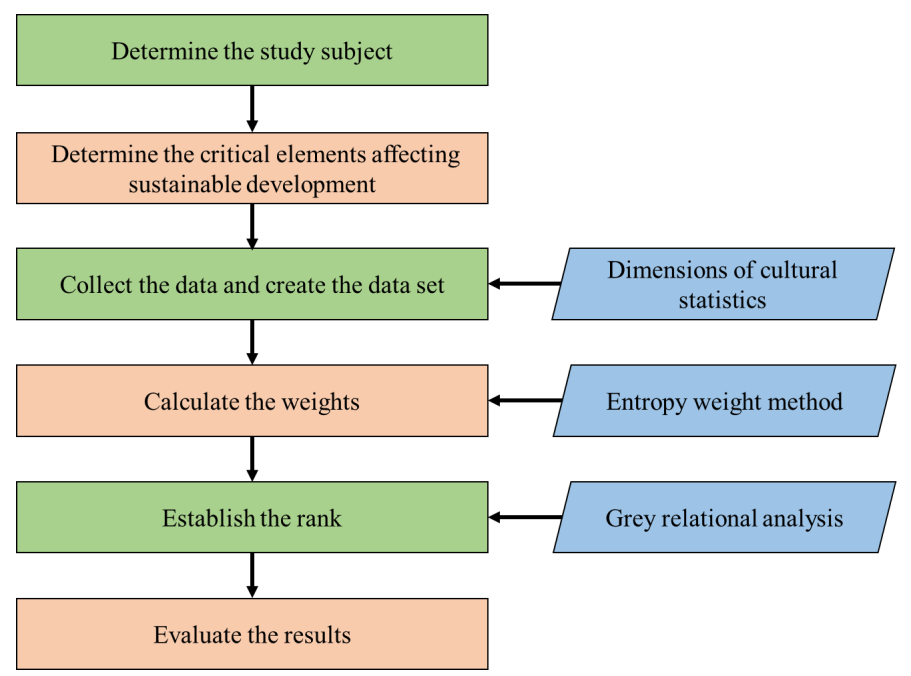

Figure 1. Methodological framework

\subsection{Entrophy}

Weight calculation methods can be categorized as subjective or objective. Subjective calculation, such as with the weighted least square method, eigenvector method, and expert evaluation, weighs attributes based on subjective preferences and may lead to biased results 
and lowered confidence levels. Objective methods, however, can remove such subjectivity and minimize interference from researchers' own perceptions. Objective methods include the entropy method and AHP. This study adopted the entropy method to weigh various factors that influence CCIs and introduced a GRA system to sequence those factors. Thus, the interference of manual operations was reduced, and the credibility and accuracy of obtained results were enhanced. The detailed calculation steps are presented in Appendix A.

\subsection{Grey relational analysis}

Grey system theory enables researchers to conduct relational analysis and construct a model to examine unclear or incomplete data in a system. This theory may be used to discuss and analyze a system to establish predictions and decision-making methods. It can effectively address the uncertainty of objects, multi-input discrete data, and insufficient data. Research covering grey generation, grey relational analysis, grey construction, grey prediction, grey decisions, and grey control in GRA was published in 1979 (Deng, 1989). GRA focuses on conducting quantitative comparative analysis of development dynamics concerning different elements in a grey system (a system with information partially known and partially unknown).

GRA defines a method and denotes the primary connections between factors in a system to facilitate the identification of the major factors that influence development, which allows researchers to grasp key features of an object (Kuo et al., 2008). For two systems or two factors within a system, the measure of the degree of correlation between them over time or due to a change of subject is called the relational grade. In GRA, similarity or dissimilarity between factors regarding their development is called the grey relational grade.

In this study, GRA and entropy weight were applied to evaluate the critical elements affecting sustainable development. The objective of the study was to evaluate the application of grey entropy degrees to critical elements affecting sustainable development. The entropy weight decomposed from the matrix can be calculated by multiplying the grey relational coefficient with the corresponding weight of the criterion.

\subsection{Steps of grey relational analysis}

Grey relational grade is a numerical measure function joining the four axioms in a grey system. Grey relational grade is a common measure in the GRA of grey systems that describes the relevancy between sequences. The following list summarizes the computing process of GRA:

1. Defining sequences for analysis: If, among all sequences, a reference sequence is provided and others are comparability sequences, a localized grey relational grade is used. If any sequence can be the reference sequence, a globalization grey relational grade is used. The reference sequence is the set of optimal target values of all factors, and the comparability sequence is that of the performance values of each solution.

2. Standardizing original variables between sequences: For this study, variables with higher values can enhance the advantages of factors influencing CCIs. Hence, a higher target value is considered desirable. 
3. Computing the grey relationship coefficient: Before calculating the grey relationship coefficient, the identification coefficient should be defined. Identification coefficients allow the reference value and comparability coefficients to be better distinguished. The value can be adjusted according to the actual objective, and adjustment does not alter the result because changes in the identification coefficient value only alter the relational value and not the rank of grey relational grades. In general, identification is valued at 0.5 , but this can be adjusted to obtain more distinct results. To describe the performance of each city, the identification coefficient herein is valued at 0.5 .

$$
\gamma(x i(k), x j(k))=\frac{\Delta \min +\zeta \Delta \max }{\Delta_{i j}+\zeta \Delta \max },
$$

in which $\chi i(\chi i(1), \chi i(2) \ldots, \chi i(m)) \in X, i=1,2, \ldots, n, \chi i(k)$ is a random element of the sequence, $k=1,2, \ldots, m, x_{i}$ is the reference sequence, and $x_{j}$ is the comparability sequence.

$\Delta_{i j}$ is the absolute value of the difference between $x_{i}(k)$ and $x_{j}(k)$,

$$
\Delta_{i j}=\left|x_{i}(k)-x_{j}(k)\right|
$$

$$
\Delta \max =\max _{\forall i \forall j} \max _{\forall k} \Delta_{i j}|x i(k)-x j(k)|, \Delta \min =\min _{\forall i \forall j \forall i \forall j} \Delta_{i j}|x i(k)-x j(k)|, \zeta=0.5 .
$$

4. Computing grey relational grade: After the grey relationship coefficient is derived, it is multiplied with the weight of each criterion to obtain the grey relational grade of $\chi i$ and $\chi j$ sequences according to the following equation:

$$
\Gamma(x i, x j)=\sum_{k=1}^{n}\left(\beta_{k} \gamma(x i(k), x j(k)),\right.
$$

in which $\beta_{k}$ is the weight value. Weights are assigned to factors according to their influence and importance. In this study, entropy weight was applied to define the relational weight of each factor influencing the industry, then those were multiplied with the grey relationship coefficient to maintain objectivity. The weighted average aggregation is the grey relational grade. An increase in the indicator represents an increase in the country's performance.

5. Ranking grey correlation: After the grey relational grade is derived, results are ranked to grey relationship. As $\Gamma(x i, x j)$ increases, the variable's grey relational grade also increases, which indicates that it is closer to the reference sequence and performs well.

In this study, cities comprised the sample, and the increased grey relational grade reflected that the factors concerning each city were close to influencing CCIs. By ranking the results for each city, the strength of the factors was revealed.

\subsection{Dimensions of cultural statistics}

Indicators of core cultural and creativity activity should be separated from those that measure the city background and social and economic achievements (Stano \& Węziak-Białowolska, 
2017). Creative cities should be driven by CCIs that rely on creative talent to boost development. Therefore, living and working environments that attract talent should be developed. Such factors are essential to CCI-focused cities. These cities adopt novel industries, and creativity and related spaces comprise major content, whereas industry comprises subcontent, with citizens, consumers, and visitors as subjects. Yigitcanlar and Lönnqvist (2013) accounted for regional policy background and possible means of improving the regional status and competitiveness to develop a method for evaluating sustainable development. Scholars have reported on current methodologies for measuring practices relate to market circulation and expansion, talent cultivation and cooperation, industrial conglomeration, and cross-segment integration (Pratt, 2011; Rodrigues \& Franco, 2018; Stano \& Węziak-Białowolska, 2017). If research on CCIs is limited to analysis of the census data of businesses and service industries, core elements are impossible to identify. The current mechanism for measuring policies should be prioritized. The framework and content of the four dimensions of cultural statistics are described briefly as follows:

1. Culture and administration: This describes the status and progress of cultural administration by governments in Taiwan and incorporates planning, the deployment of cultural measures, and the support provided to them.

2. Culture and education: This reflects the status of talent cultivation in each cultural pursuit, addresses the cultivation of cultural literacy, and includes professional training provided by government, schools, and society. This dimension focuses on factors that spur cultures to effectively promote growth.

3. Culture and society: This dimension includes practices related to culture engaged in by the public, such as coordination and support between supply and demand that create a cultural environment from citizens' perspectives. Cultural resources; art performance; books and publications; films and television programs; popular music; and cultural exchange, participation, and consumption belong to this dimension. It demonstrates the development of the cultural life of the masses.

4. Culture and industry: This dimension includes the production and distribution of culture from the market perspective; for instance, analyses of industry status that demonstrate industry development in both the public and private sectors and cover output, human resources, culture-related trades, and jobs.

In this study, we employed the entropy weight method to obtain the objective weights of each variable. Next, the grey relational analysis was applied to analyze the factors influencing the CCIs of each city. Finally, the key influencing factors were sorted and discussed.

\subsection{Measuring variables}

Following the four-dimensional structure of the Ministry of Culture in Taiwan and the authoritative literature and combining these with the criteria of indicator selection, 14 variables were selected and the objective weight of each was calculated based on the entropy method. Then, GRA was adopted to analyze factors influencing CCIs in each city. Finally, key factors were sequenced and ranked for discussion. The variables and measurements are defined in Appendix B. 


\section{Cultural resource allocation in Taiwanese cities}

CCIs are increasingly critical to economic well-being, and their proponents suggest that human creativity is the ultimate economic resource. Cultural and creative clusters have their own unique styles and forms because of their history, geographical environment, and demographic structure. Featuring tight social and economic structures and relationships and diverse cultural facilities, landscapes, and migrants, cities can accommodate the emergence of creative clusters. Having a foundation upon which CCIs can blossom is highly reliant on unique local cultural resources and traditions. This is clear, especially given globalized competition across cities. Cities' and countries' experiences reveal that the revitalization of cities driven by cultural and creative development is a strong trend (Goldberg-Miller, 2019; Otmazgin \& Ben-Ari, 2012; Stano \& Węziak-Białowolska, 2017). Similar to other East Asian countries, in the past decade, Taiwan has experienced the propagation and revision of creative city policies, mainly arising from Western urban planning models. The pace at which this has happened sometimes results in inadequate reflection of the adaptability of culture and creativity-led urban regeneration plans (Ursic, 2019). Landoni et al. (2020) pointed out that creative and cultural firms could overcome resource constraints through business model innovation. The empirical results of Chang and Lee (2015) showed that Taiwan's government policies were the main driving force for the development of Taiwan's CCI. A positive average growth rate could be sustained for this development even in the event of a sudden economic downturn. Wu et al. (2020) also highlighted that the integration of cultural tourism and games can aid the design and development of Taiwan's tourism and related industries.

Therefore, the key to building localized CCIs rests in defining the unique and local cultural potential of communities and using crucial community elements to gather people together. In Taiwan, the original notion of community building addresses the estrangement generated from the urbanization and globalization of Taiwan and consequently develops communication of shared values in life, culture, and industry to lead to an environment wherein CCIs may be developed. Against this background, community building is entangled with CCI development. By taking advantage of the soft power of regional cultural characteristics, regional brands and development can be promoted. Each city can shape its own cultural landscape.

\section{Cultural resource allocation in Taiwanese cities}

\subsection{Descriptive statistics}

Descriptive statistics concerning each indicator are presented in Table 1. The cultural industry is a critical aspect of city development strategies to address challenges posed by globalization. City marketing can stimulate the export of local cultural products to global and regional markets. The budget of local governments for culture expenditure ranges from NT\$92,085 to NT\$14,199,385 in the cities included in this study. However, the percentage of the culture budget relative to the total budget of local governments ranged from $0.29 \%$ to $9.42 \%$. The two indicators revealed that investment in the development of CCIs varied drastically among cities. The development of modern cities cannot be achieved without cultural industries. This requires local city governments to consider the cultural industry as a crucial component and 
balance the progress of cultural industries in each city. By making industries with regional characteristics the driving force of economic development, CCIs with regional characteristics can become an asset for promoting tourism and other local industries.

Table 1. Descriptive statistics

\begin{tabular}{|l|c|c|c|c|}
\hline \multicolumn{1}{|c|}{ Indicators of core cultural and creativity activity } & Min. & Max. & Average & St. dev \\
\hline Local government budget for culture expenditure & 92,085 & $14,199,385$ & $1,403,463$ & $2,346,377$ \\
\hline $\begin{array}{l}\text { Local government budget for culture expenditure } \\
\text { per capita }\end{array}$ & 233 & 11,261 & 1,586 & 1,967 \\
\hline $\begin{array}{l}\text { Percentage of local government budget for culture } \\
\text { expenditure in the total local government budget }\end{array}$ & 0.29 & 9.42 & 2.35 & 1.44 \\
\hline $\begin{array}{l}\text { Headcount of the Ministry of Culture and its } \\
\text { subordinate organs }\end{array}$ & 21.00 & 791.00 & 195.15 & 223.48 \\
\hline Number of cultural volunteers in local government & 8 & 3,866 & 862 & 1,070 \\
\hline Rate of participation in culture & 71.00 & 96.00 & 82.45 & 4.61 \\
\hline Number of applications for ISBN & 8,613 & $51,130,727$ & $1,497,236$ & $5,145,429$ \\
\hline $\begin{array}{l}\text { Percentage of higher education graduates from cul- } \\
\text { ture-related narrower subjects in total number of } \\
\text { graduates }\end{array}$ & 14.00 & 64.00 & 28.37 & 9.47 \\
\hline Total budget of community building & 2.00 & 96.00 & 20.31 & 12.38 \\
\hline $\begin{array}{l}\text { Monuments, historic buildings, settlements, cultural } \\
\text { landscape and ruins }\end{array}$ & 27.00 & 431.00 & 105.62 & 80.29 \\
\hline $\begin{array}{l}\text { Mean number of places for cultural and art activities } \\
\text { per 10,000 people }\end{array}$ & 0.74 & 30.06 & 3.94 & 5.58 \\
\hline Number of cultural and art activities & 124 & 9,852 & 2,663 & 2,723 \\
\hline $\begin{array}{l}\text { Number of companies in cultural and creative } \\
\text { industries }\end{array}$ & 218 & 18,979 & 2,971 & 4,206 \\
\hline Number of employees in culture-related industries & 19 & 1,961 & 530 & 524 \\
\hline
\end{tabular}

\subsection{Determination of criteria weights by using entropy weight}

This study evaluated the performance of CCIs in each city. In the model, entropy weight was applied to appropriately weigh each evaluative indicator, and GRA was adopted to quantify and compare qualitative information to minimize the impact of subjectivity and enhance the accuracy of evaluations, thereby providing a new approach for evaluating CCI performance. Furthermore, the model can serve as an objective and scientific reference for the public sector and decisionmaking units when adjusting citywide social and economic interactions and resource allocation. With certain resource allocation measures, the model can prioritize the provision of cultural and creative resources to effectively improve a city's cultural and creative resource-generating capacity and enhance the capacity of each individual city in a network. Entropy was first adopted to calculate the importance of variables through operational efficiency of CCIs in each city, which were then ranked accordingly. GRA was then applied to calculate the weight of each variable with various dimensions, and the grey relational grade of each variable was computed to judge the advantages and disadvantages of each city's performance. These are explained in order in Table 2. 
Table 2. Weight of each dimension

\begin{tabular}{|c|c|c|}
\hline Dimension & Variables & Weight \\
\hline \multirow{5}{*}{$\begin{array}{l}\text { Culture } \\
\text { and admi- } \\
\text { nistration }\end{array}$} & Local government budget for culture expenditure & 0.252 \\
\hline & Local government budget for culture expenditure per capita & 0.185 \\
\hline & $\begin{array}{l}\text { Percentage (\%) of local government budget for culture expenditure in } \\
\text { total local government budge }\end{array}$ & 0.167 \\
\hline & Headcount of the Ministry of Culture and its subordinate organs & 0.197 \\
\hline & Number of cultural volunteers in local government & 0.199 \\
\hline \multirow{4}{*}{$\begin{array}{l}\text { Culture and } \\
\text { education }\end{array}$} & Rate of participation in culture & 0.025 \\
\hline & Number of applications for ISBN & 0.877 \\
\hline & $\begin{array}{l}\text { Percentage (\%) of higher education graduates in culture-related } \\
\text { narrower subjects in total number of graduates }\end{array}$ & 0.036 \\
\hline & Total budget of community building (million NT\$) & 0.062 \\
\hline \multirow{3}{*}{$\begin{array}{l}\text { Culture and } \\
\text { society }\end{array}$} & Monuments/historic buildings/settlements/cultural landscape/ruins & 0.346 \\
\hline & Mean number of places for cultural and art activities per 10,000 people & 0.337 \\
\hline & Number of cultural and art activities & 0.317 \\
\hline \multirow{2}{*}{$\begin{array}{l}\text { Culture and } \\
\text { industry }\end{array}$} & Number of companies in cultural and creative industries & 0.467 \\
\hline & Number of employees in culture-related industries & 0.533 \\
\hline
\end{tabular}

Entropy was then adopted to analyze the weight change of each indicator of operational efficiency between 2012 and 2017. The weight of each dimension is listed in Table 2. For culture and administration, the local government budget for culture was observed to be the most important factor from 2012 to 2017 in Figure 2, with an average weight of 0.252 , and the weights of the head count of the Ministry of Culture and its subordinate organs and the number of cultural volunteers in local government were 0.197 and 0.199 , respectively, illustrating the primary importance of government budgets and human resource allocation coordination. The changes in each variable revealed a budget increase of local government culture expenditure per capita annually, which is a central aspect of enhancing administrative performance.

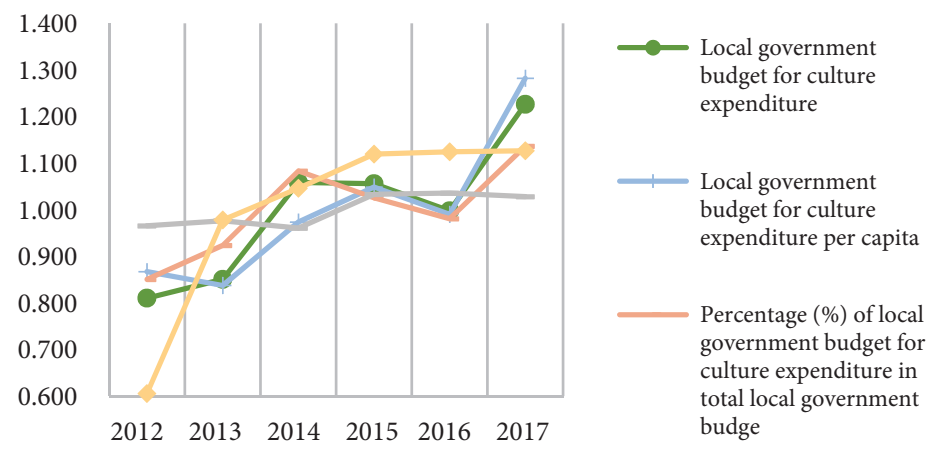

Figure 2. Cultural and administration variables 
The results for culture and education are present in Figure 3, the number of international standard book number (ISBN) applications had an average weight of 0.877 , which was significantly higher than that of other indicators, thereby indicating the outstanding importance of new publications to culture and education. However, in the era of science and technology, the popularization of mobile devices has promoted digital reading, which poses a great structural challenge to book publication and the related industrial chain. As physical bookstore sales continue to decline, downstream book sales channels are increasingly confronted with difficulties associated with rising operational costs and decreasing sales, and upstream book publishers are affected by high book return rates and challenging operational costs. Thus, decision-making for the book industry has become rather conservative. The government should amend relevant laws to allow the sales of magazines, books, and newspapers from registered newspaper and periodical offices to be exempt from operational taxes to stimulate production.
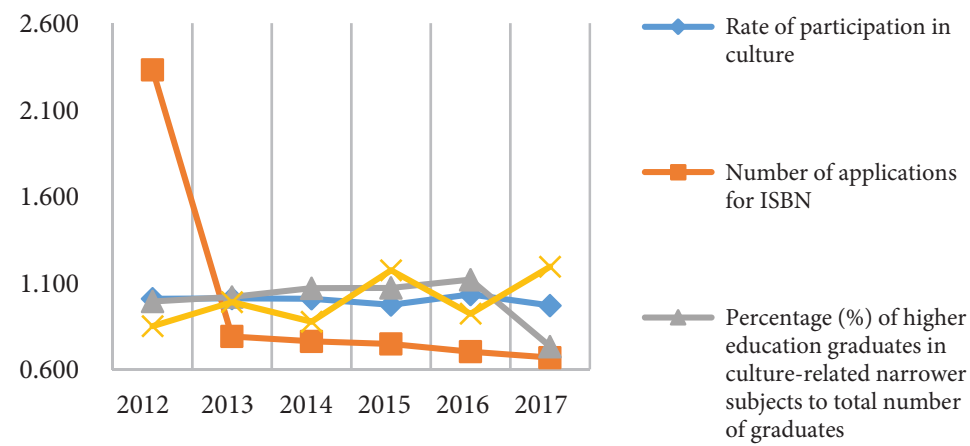

Figure 3. Cultural and educational variables

Figure 4 shows the results of culture and society, variation among the three indicators was not explicit. The number of places for both cultural and art activities remained stable; however, local governments should provide dedicated infrastructure for these activities. Moreover, governments should take the initiative in creating environments that attract creative talent. Given the trend of regional integration, it is suggested that demographic changes (aging and subreplacement fertility) be considered as well.

In the last dimension, culture and industry, as shown in Figure 5, the mean weight of the number of employees in culture-related industries was 0.533 , which was higher than the

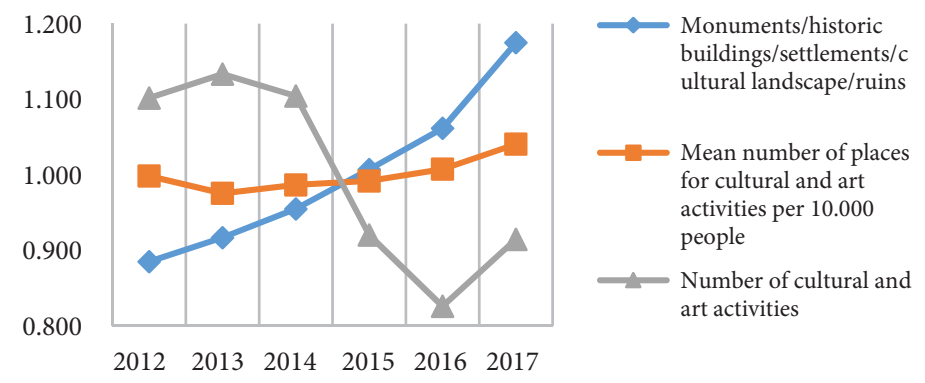

Figure 4. Cultural and societal variables 


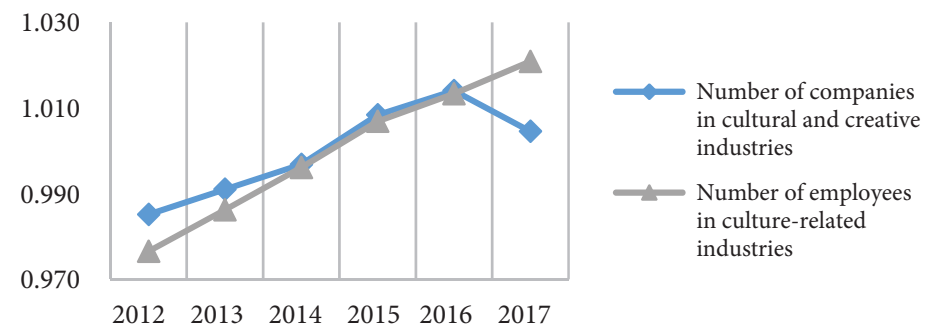

Figure 5. Cultural and industrial variables

weight of the number of companies in these industries, 0.467 - the latter of which signifies the employment environment of CCIs. As an emerging industry characterized by progress in communication technology and transformation from a scale economy into a microindustry in Taiwan, CCIs overall have increasingly become highly flexible and creative sources of employment. Regarding company scale, companies in CCIs typically employ 5 to $10 \mathrm{em}$ ployees, and the content of work is professional-oriented and focused on problem solving and creation. CCIs rely on the driving force of creative talent. Cities should provide diverse living environments to attract such talent. CCIs transform cities into areas where creativity is generated and cultivated.

\subsection{Performance evaluation with grey relational analysis}

In this section, the weight of each indicator (Table 2) derived from entropy was combined with the grey data to obtain the grey relational grade (Table 3) of each city. High values indicate high proximity to the reference sequence, which signifies robust cultural development. The results were then ranked to establish the grey relationship rank, which ranks cultural development quality.

The grey relational coefficients in Table 3 revealed that Taitung County outperformed other cities in both culture and administration and culture and industry. It is located in the southeast of Taiwan, where economic performance has long remained weak; however, Taitung managed to develop the region by emphasizing CCI development, which improved the constantly widening gap between urban and rural development and avoided the effects of imbalanced regional development that otherwise has plagued Taiwan's overall progress. Furthermore, CCI development stimulated the reasonable exploitation of local resources, which effectively prevented regional stagnation and optimized resource allocation for areas needing stimuli, thereby promoting regional development. Such measures also helped prevent blind and irrational government investment.

For culture and education, the average coefficient was 0.918 , which exhibited the highest overall performance among the four dimensions. This indicated that local governments have realized that the economic benefits of culture are not limited to certain CCIs but to the overall economy. Through stimulus policies, communities have effectively been built to revitalize regional economies.

For culture and society, the best performance was observed in Chiayi City. However, the coefficients of Tier 1 Taipei City and Taichung City were only 0.662 and 0.731 , respectively, 
indicating that subsidizing and guiding local spaces, variations in population aging, and losses between cities and urban and rural areas result in the current distribution of cultural facilities and population density often being mismatched.

Table 3. Grey relational coefficients

\begin{tabular}{|l|c|c|c|c|c|}
\hline \multicolumn{1}{|c|}{ City } & $\begin{array}{c}\text { Culture and } \\
\text { administration }\end{array}$ & $\begin{array}{c}\text { Culture and } \\
\text { education }\end{array}$ & $\begin{array}{c}\text { Culture and } \\
\text { society }\end{array}$ & $\begin{array}{c}\text { Culture and } \\
\text { industry }\end{array}$ & Average \\
\hline Keelung City & 0.454 & 0.403 & 0.533 & 0.422 & 0.453 \\
\hline Taipei City & 0.720 & 0.693 & 0.662 & 0.440 & 0.629 \\
\hline New Taipei City & 0.707 & 0.947 & 0.789 & 0.665 & 0.777 \\
\hline Taoyuan City & 0.961 & 0.978 & 0.999 & 0.995 & 0.983 \\
\hline Hsinchu City & 0.978 & 0.993 & 0.925 & 0.986 & 0.970 \\
\hline Hsinchu County & 0.943 & 1.000 & 0.947 & 0.965 & 0.964 \\
\hline Miaoli County & 0.745 & 0.873 & 0.632 & 0.533 & 0.696 \\
\hline Taichung City & 0.880 & 0.973 & 0.731 & 0.792 & 0.844 \\
\hline Changhua County & 0.937 & 0.994 & 0.944 & 0.976 & 0.963 \\
\hline Nantou County & 0.920 & 0.996 & 0.927 & 0.935 & 0.945 \\
\hline Yunlin County & 0.926 & 0.980 & 0.995 & 0.996 & 0.974 \\
\hline Chiayi City & 0.944 & 0.985 & 1.000 & 0.982 & 0.978 \\
\hline Chiayi County & 0.576 & 0.734 & 0.630 & 0.656 & 0.649 \\
\hline Tainan City & 0.754 & 0.867 & 0.669 & 0.561 & 0.713 \\
\hline Kaohsiung City & 0.979 & 0.996 & 0.907 & 0.881 & 0.941 \\
\hline Pingtung County & 0.967 & 0.981 & 0.972 & 0.994 & 0.979 \\
\hline Taitung County & 1.000 & 0.988 & 0.942 & 1.000 & 0.982 \\
\hline Hualien County & 0.882 & 0.990 & 0.861 & 0.991 & 0.931 \\
\hline Yilan County & 0.873 & 0.982 & 0.793 & 0.944 & 0.898 \\
\hline Penghu County & 0.787 & 0.998 & 0.815 & 0.933 & 0.884 \\
\hline Average & 0.847 & 0.918 & 0.834 & 0.832 & 0.858 \\
\hline
\end{tabular}

\subsection{Regional comparison analysis}

Currently, Table 4 shows that the scope of overall planning of city development in Taiwan is divided into four regions (north, central, south, and east), which was a reference framework for regional analysis, as presented in Figure 5. Table 4 reveals that grey relational coefficients of the four dimensions in the four regions. According to results obtained for each region, the results for the four dimensions of culture and administration, culture and education, culture and society, and culture and industry were $0.886,0.990,0.853$, and 0.967 , respectively, thus outperforming other regions and revealing how cities in the eastern region and offshore islands took more advantage of investment in cultural resources than cities in the western region; thus, the results of cultural development in the four dimensions began to take shape. However, the results indicated that industry guidance can help balance regional development across cities, and this has caused successful resource allocation for CCIs. 
Table 4. Grey relational coefficients of the four dimensions in the four regions

\begin{tabular}{|l|l|c|c|c|c|}
\hline Region & \multicolumn{1}{|c|}{ Cities } & $\begin{array}{c}\text { Culture and } \\
\text { adminis- } \\
\text { tration }\end{array}$ & $\begin{array}{c}\text { Culture } \\
\text { and } \\
\text { education }\end{array}$ & $\begin{array}{c}\text { Culture } \\
\text { and } \\
\text { society }\end{array}$ & $\begin{array}{c}\text { Culture } \\
\text { and } \\
\text { industry }\end{array}$ \\
\hline North & $\begin{array}{l}\text { Keelung City, Taipei City, New } \\
\text { Taipei City, Taoyuan City, Hsinchu } \\
\text { City, Hsinchu County }\end{array}$ & 0.794 & 0.836 & 0.809 & 0.745 \\
\hline Central & $\begin{array}{l}\text { Miaoli County, Taichung City, } \\
\text { Changhua County, Nantou County, } \\
\text { Yunlin County }\end{array}$ & 0.882 & 0.963 & 0.846 & 0.847 \\
\hline South & $\begin{array}{l}\text { Chiayi City, Chiayi County, Tainan } \\
\text { City, Kaohsiung City, Pingtung } \\
\text { County }\end{array}$ & 0.844 & 0.913 & 0.836 & 0.815 \\
\hline East & $\begin{array}{l}\text { Taitung County, Hualien County, } \\
\text { Yilan County, Penghu County }\end{array}$ & 0.886 & 0.990 & 0.853 & 0.967 \\
\hline
\end{tabular}

From the regional comparison data presented in Figure 6, the northern region's culture and administration, culture and education, culture and society, and culture and industry scores were $0.794,0.836,0.809$, and 0.745 , respectively, which were lower than those of the other regions. As a highly populous and business development-intensive region, the north has witnessed comparatively insufficient cultural development in all dimensions; however, this indicates that this region still has growth potential. This study revealed that during the development of resource allocation strategies for CCIs, these industries were considered in national resource allocation strategies. By combining culture and economic industries to create substantial value-adding benefits, jobs can be created, and local livelihoods can be improved. By promoting local cultural construction and strengthening cultural development, cultural and economic industrial development can be driven, and a region's competitive edge may be created and empowered. Long-term industry development planning policies can balance the development of culture, the economy, and the city.

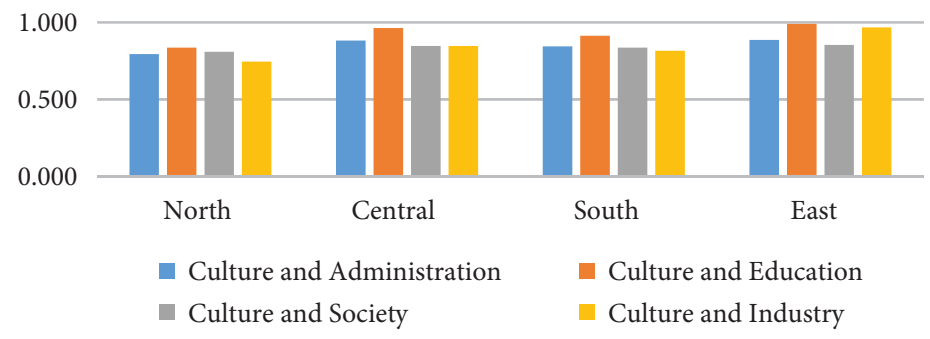

Figure 6. Regional comparison

Because Taiwan is undergoing structural adjustment and is innovation driven with balanced development, cultural content is a crucial catalyst for adding value to culture and creativity and catalyzing cultural communication and translation to boost people's confidence in their culture. The combination of culture, creativity, and technology can instantiate the future life people have envisioned. Two vital questions remain: (1) How do we construct a social environment with enriched culture and creativity? (2) How do we combine technology 
and creativity to boost the CCI economy? In recent years, the development of CCIs has been stimulated globally, including in developed countries with mature economies and cultures. CCIs boost economic growth, facilitate the industrial upgrading of countries, and generate output and added value for cities.

\section{Conclusions}

This study introduces entropy weight and GRA in an evaluation indicator system. This model considers the ambiguity, complexity, and quantification difficulty of value creation and resource allocation for CCIs. However, in real sustainable development practice, the majority of criteria are based on incomplete information. This study is one of the first to theoretically evaluate critical elements that affect sustainable development by using grey and entropy theory with respect to CCIs. The results of this study illustrate that under the guidance of government policies, compared with the industrial development of cities in Western Taiwan, cities in Eastern Taiwan and the outlying islands have gradually demonstrated results in various aspects of cultural development by drawing upon their cultural resources. Besides, it also means that the current implementation of Taiwan's present resource allocation strategy for CCIs is successful.

This policy can indeed balance the regional development of cities through industry guidance. CCI investment more benefited eastern regions than northern regions, and cultural resource preservation, industrial activation, cultural tourism marketing, and environmental improvement benefits were more noted in that region. For long-term recommendations, note that monument conservation is mostly promoted by public sectors, but many members of the public are resistant to the idea. The encouragement of the private sector to invest in cultural conservation can transform industry and promote tourism. For example, the public sector can reward the private sector for emphasizing conservation or provide tax breaks to encourage shops to join community associations or activity funds to share benefits. GRA aggregates lines of sequence based on components, elements, and subsets and judged their relevancy according to their similarity. The operation of CCIs in each city was evaluated, and entropy weight was applied to define the weight of each evaluative indicator in the model. This method represents a new approach for evaluating CCI operations. Furthermore, this is an objective and scientific reference for the public sector and decision-making units; the findings can be relevant when adjusting social and economic interactions and resource allocation in whole cities. With certain resource allocations, cities can prioritize the provision of cultural and creative resources to effectively improve its cultural and creative resource-generating capacity and enhance its capacity in the network of cities. Therefore, only by thoroughly examining the relationships between cities, culture, and globalization to avoid the adoption of policies that pursue the quickest satisfaction of demands can we reconstruct a new economy of efficiency and value creation.

This study has certain limitations. Traditionally, the industrial chain was divided into upstream and downstream subindustries. Nevertheless, this method of division cannot interpret the current status quo and trends of CCIs in which the boundaries between subindustries are blurry. The value chain has developed into a mesh model, and the cultural content in- 
dustry has gradually shifted from a linear industrial chain toward a network-based industrial ecosystem. However, in this network-based ecosystem, past experiences gradually become inapplicable to current development. Thus, future studies should adjust their research methods and data measurements accordingly. Legitimate criticism of conventional GRA is its omission of the time dimension. A possible future direction of dynamic efficiency research is considering the industry characteristics described by Dahooie et al. (2018) or using resource regulation and control to improve dynamic efficiency models. This study has designed an evaluation model for the key success factors of CCIs. Moreover, through empirical model evaluation, the study has provided some suggestions for decision-makers in the cultural and creative sector to alleviate the gap between urban and rural resources and promote a balanced development of Taiwan's CCIs.

\section{Funding}

This research is supported by the Ministry of Science and Technology, Taiwan, R.O.C. under Grant No. MOST 107-2410-H-027-008.

\section{Author contributions}

Yueh-Cheng WU and Sheng-Wei LIN conceived the study and were responsible for the design and development of the data analysis.

\section{Disclosure statement}

The authors declare that they have no conflict of interest.

\section{References}

Baraldi, E., \& Havenvid, M. I. (2016). Identifying new dimensions of business incubation: A multi-level analysis of Karolinska Institute's incubation system. Technovation, 50, 53-68. https://doi.org/10.1016/j.technovation.2015.08.003

Bhansing, P. V., Hitters, E., \& Wijngaarden, Y. (2018). Passion inspires: Motivations of creative entrepreneurs in creative business centres in the Netherlands. The Journal of Entrepreneurship, 27(1), 1-24. https://doi.org/10.1177/0971355717738589

Boccella, N., \& Salerno, I. (2016). Creative economy, cultural industries and local development. Procedia-Social and Behavioral Sciences, 223, 291-296. https://doi.org/10.1016/j.sbspro.2016.05.370

Budge, K. (2019). Making in the city: Disjunctures between public discourse and urban policy. Australian Geographer, 50(2), 185-199. https://doi.org/10.1080/00049182.2018.1503045

Chang, W. S., \& Lee, Y. H. (2015). Policy momentum for the development of Taiwan's cultural creative industries. Current Issues in Tourism, 18(11), 1088-1098. https://doi.org/10.1080/13683500.2014.992395

Dahooie, J., Vanaki, A., Mohammadi, N., \& Firoozfar, H. (2018). Selection of optimal variant route based on dynamic fuzzy GRA. Decision Science Letters, 7, 523-534.

https://doi.org/10.5267/j.dsl.2017.11.004 
Deng, J. (1989). Introduction to grey system theory. The Journal of Grey System, 1(1), 1-24. http://www.researchinformation.co.uk/grey/IntroGreySysTheory.pdf

Florida, R. (2002). The rise of the creative class (Vol. 9). Basic books.

Gangurde, S. R. (2016). Benchmark the best factory data collection system (FDC) using AHP-GRA method. Benchmarking: An International Journal, 23(2), 359-370. https://doi.org/10.1108/BIJ-03-2014-0023

Goldberg-Miller, S. B. (2019). Creative city strategies on the municipal agenda in New York. City, Culture and Society, 17, 26-37. https://doi.org/10.1016/j.ccs.2018.08.004

Gottdiener, M. (2019). New urban sociology. In A. Orum (Ed.), The Wiley Blackwell encyclopedia of urban and regional studies (pp. 1-5). McGraw Hill.

Hashemi, S. H., Karimi, A., \& Tavana, M. (2015). An integrated green supplier selection approach with analytic network process and improved Grey relational analysis. International Journal of Production Economics, 159, 178-191. https://doi.org/10.1016/j.ijpe.2014.09.027

Hauge, E. S., Pinheiro, R. M., \& Zyzak, B. (2018). Knowledge bases and regional development: Collaborations between higher education and cultural creative industries. International Journal of Cultural Policy, 24(4), 485-503. https://doi.org/10.1080/10286632.2016.1218858

Hernández-Mogollón, J. M., Duarte, P. A., \& Folgado-Fernández, J. A. (2018). The contribution of cultural events to the formation of the cognitive and affective images of a tourist destination. Journal of Destination Marketing \& Management, 8, 170-178. https://doi.org/10.1016/j.jdmm.2017.03.004

Irankhahi, M., Jozi, S., Farshchi, P., Shariat, S., \& Liaghati, H. (2017). Combination of GISFM and TOPSIS to evaluation of Urban Environment Carrying Capacity (case study: Shemiran City, Iran). International Journal of Environmental Science and Technology, 14, 1317-1332. https://doi.org/10.1007/s13762-017-1243-0

Kim, C. (2017). Locating creative city policy in East Asia: Neoliberalism, developmental state and assemblage of East Asian cities. International Journal of Cultural Policy, 23(3), 312-330. https://doi.org/10.1080/10286632.2015.1048242

Kuo, Y., Yang, T., \& Huang, G. W. (2008). The use of grey relational analysis in solving multiple attribute decision-making problems. Computers x Industrial Engineering, 55(1), 80-93. https://doi.org/10.1016/j.cie.2007.12.002

Landoni, P., Dell'era, C., Frattini, F., Petruzzelli, A. M., Verganti, R., \& Manelli, L. (2020). Business model innovation in cultural and creative industries: Insights from three leading mobile gaming firms. Technovation, 92, 102084. https://doi.org/10.1016/j.technovation.2019.102084

Lu, C., \& Chang, J. L. (2016). Beijing cultural and creative industry policy effect evaluation based on fuzzy comprehensive evaluation. Cluster Computing, 19, 2133-2143.

Maryunani, S. R., \& Mirzanti, I. R. (2015). The development of entrepreneurship in creative industries with reference to Bandung as a creative city. Procedia-Social and Behavioral Sciences, 169, 387-394. https://doi.org/10.1016/j.sbspro.2015.01.324

Ochoa, E. A., \& Ramírez, P. M. C. (2018). Cultural industries and spatial economic growth a model for the emergence of the creative cluster in the architecture of Toronto. City, Culture and Society, 14, 47-55. https://doi.org/10.1016/j.ccs.2018.03.001

Otmazgin, N., \& Ben-Ari, E. (2012). Cultural industries and the state in East and Southeast Asia. In N. Otmazgin \& E. Ben Arie (Eds.), Popular culture and the state in East and Southeast Asia (pp. 3-26). Routledge. https://doi.org/10.4324/9780203801536

Pereira Roders, A., \& van Oers, R. (2011). Bridging cultural heritage and sustainable development. Journal of Cultural Heritage Management and Sustainable Development, 1(1), 5-14. https://doi.org/10.1108/20441261111129898

Pratt, A. C. (2011). The cultural contradictions of the creative city. City, Culture and Society, 2(3), 123-130. https://doi.org/10.1016/j.ccs.2011.08.002 
Protogerou, A., Kontolaimou, A., \& Caloghirou, Y. (2017). Innovation in the European creative industries: A firm-level empirical approach. Industry and Innovation, 24(6), 587-612. https://doi.org/10.1080/13662716.2016.1263551

Rajesh, R., \& Ravi, V. (2015). Supplier selection in resilient supply chains: A grey relational analysis approach. Journal of Cleaner Production, 86, 343-359. https://doi.org/10.1016/j.jclepro.2014.08.054

Rodrigues, M., \& Franco, M. (2018). Measuring the performance in creative cities: Proposal of a multidimensional model. Sustainability, 10(11), 4023. https://doi.org/10.3390/su10114023

Safari, M., Kakaei, R., Ataei, M., \& Karamoozian, M. (2012). Using fuzzy TOPSIS method for mineral processing plant site selection. Arabian Journal of Geosciences, 5, 1011-1019. https://doi.org/10.1007/s12517-010-0234-y

Stano, P. M., \& Węziak-Białowolska, D. (2017). Measuring cultural and creative activities in European cities: Challenges and practical problems with existing indices. Creativity Research Journal, 29(3), 292-303. https://doi.org/10.1080/10400419.2017.1360066

United Nations. (2010). The United Nations Conference on Trade and Development. Creative economy (Report 2010). UNDP-UNCTAD. https://unctad.org/system/files/official-document/ditctab20103_ en.pdf

Ursic, M. (2019). Inadequate adaptation of creative city paradigm? Taiwanese cultural and creative-led urban regeneration policies through the eyes of urban development experts. Space and Polity, 23(1), 67-91. https://doi.org/10.1080/13562576.2019.1598257

Vatansever, K., \& Akgül, Y. (2018). Performance evaluation of websites using entropy and grey relational analysis methods: The case of airline companies. Decision Science Letters, 7, 119-130. https://doi.org/10.5267/j.dsl.2017.6.005

Wang, T. K., Zhang, Q., Chong, H. Y., \& Wang, X. (2017). Integrated supplier selection framework in a resilient construction supply chain: An approach via analytic hierarchy process (AHP) and grey relational analysis (GRA). Sustainability, 9(2), 289. https://doi.org/10.3390/su9020289

Wu, Y. C., Lin, S. W., \& Wang, Y. H. (2020). Cultural tourism and temples: Content construction and interactivity design. Tourism Management, 76, 103972. https://doi.org/10.1016/j.tourman.2019.103972

Yigitcanlar, T., \& Lönnqvist, A. (2013). Benchmarking knowledge-based urban development performance: Results from the international comparison of Helsinki. Cities, 31, 357-369. https://doi.org/10.1016/j.cities.2012.11.005

Yusuf, S., \& Nabeshima, K. (2005). Creative industries in East Asia. Cities, 22(2), 109-122. https://doi.org/10.1016/j.cities.2005.01.001

Zhang, L., Xu, Y., Yeh, C. H., Liu, Y., \& Zhou, D. (2016). City sustainability evaluation using multicriteria decision making with objective weights of interdependent criteria. Journal of Cleaner Production, 131, 491-499. https://doi.org/10.1016/j.jclepro.2016.04.153 